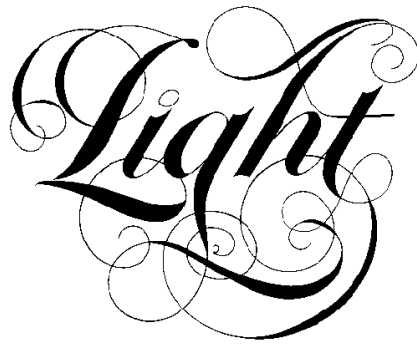

\title{
Frequency Doubling in Ga:La:S Optical Glass with Microcrystals
}

\author{
V.Pruneri, P.G.Kazansky, D.Hewak, J.Wang, H.Takebe* and D.N.Payne \\ *Department of Materials Science and Technology, \\ Kyushu University, Kasuga, Fukuoka 816, Japan.
}

\begin{abstract}
Second harmonic generation in gallium-lanthanum-sulphide (Ga:La:S) and GeS $_{2}+$ Ga:La:S glasses is investigated. It is shown that microcrystals of Ga:La:S and of $\alpha$-phase of gallium-sulphide $\left(\alpha-\mathrm{Ga}_{2} \mathrm{~S}_{3}\right)$, whose presence in the glass matrix is revealed by $x$-ray diffraction analysis, are responsible for the frequency doubling process.
\end{abstract}

Being a centro-symmetric material, glass does not normally exhibit second-order nonlinearity (SON). However, using particular treatments, second-order nonlinear $\left({ }^{(2)}\right)$ effects, e.g. electro-optic effect and optical frequency doubling, have been observed in glass materials. One way of achieving SON in optical fibres of silica glass is based on the interference between fundamental and second harmonic (SH) fields which can produce a ${ }^{(2)}$ grating as a result of a spatially modulated electrostatic field (E) and the third-order nonlinearity $\left({ }^{\left({ }^{3}\right)}\right.$ ) of the material, i.e. ${ }^{(2)}={ }^{(3)} \mathrm{E}[1,2,3]$. Another approach has been used to create a permanent $\mathrm{SON}$ in silica glass. It relies on the electric-field poling techniques, which involve high electric fields $(\sim 1 \mathrm{kV} / \mu \mathrm{m})$ at a relatively high temperature $\left(\sim 270^{\circ} \mathrm{C}\right)[4,5,6]$. The resulting $\mathrm{SON}$ is in this case limited to a thin layer (a few microns) under the anodic electrode. Beside silica, the search of other glasses, candidates for electric field poling, can represent a significant step forward to increase SON in glass materials. In particular it seems to be appropriate to investigate poling in available glass materials that have been currently used for other optical applications.

In recent years one type of glass which has been attracting growing interest is gallium-lanthanum-sulphide (Ga:La:S) since it appears to be one of the most promising host material for $1.3 \mu \mathrm{m}$ optical fibre amplifiers and an emergent material for lasers operating in the 1 to $5 \mu \mathrm{m}$ wavelength region $[7,8]$. However any nonlinear optical process, such as frequency doubling, is undesirable in these Ga:La:S based optical devices because it would represent a source of nonlinear loss and noise. On the other hand the interest in this glass is in the fact that it could be a good candidate for poling, thus making relevant a nonlinear optical study of its structure. Recently, Araujo et al. [9] reported second harmonic generation (SHG) in a 3-mm-thick praseodymium-doped Ga:La:S glass which was not treated in the usual ways, which result in second-order nonlinearities (cf. reference 1-6). It was also suggested that the SON had a different nature than in refs.1-6, i.e. it was not the result of a photoinduced process or any kind of poling. Here we investigate SHG in GLS based glasses observing, for the first time to our knowledge, that microcrystals of Ga:La:S and $\alpha$-phase of gallium sulfide $\left(\alpha-\mathrm{Ga}_{2} \mathrm{~S}_{3}\right)[10,11]$ are responsible for the SON.

Three samples were studied. The first sample (A) was a $\mathrm{Pr}^{3+}$-doped Ga:La:S glass prepared by conventional melt quenching techniques. Starting materials of $\mathrm{Ga}_{2} \mathrm{~S}_{3}$ and $\mathrm{La}_{2} \mathrm{~S}_{3}$ were weighed and mixed in the appropriate amounts to achieve a molar composition of $70 \mathrm{~mol} \% \mathrm{Ga}_{2} \mathrm{~S}_{3}$ and $30 \%$ mol La $\mathrm{S}_{3}$ with 500 parts per million of $\mathrm{Pr}^{3+}$ by weight. Powders were melted at $1150{ }^{\circ} \mathrm{C}$ for eight 
hours in a vitreous carbon then rapidly quenched to room temperature before annealing at $530{ }^{\circ} \mathrm{C}$ for 24 hours. This sample showed no presence of any crystalline phase. In sample B, the fabrication procedure was identical however quenching was less rapid. This slower cooling resulted in the growth of microcrystals randomly dispersed in the glass matrix and with typical dimensions of $10-30 \mu \mathrm{m}$. This is evident in figure 1 (a), taken using a microscope (this was also evident by naked-eye). The third sample (C) was an early experimental sample of composition $10 \mathrm{GeS}_{2} 90\left(70 \mathrm{Ga}_{2} \mathrm{~S}_{3} 30 \mathrm{La}_{2} \mathrm{~S}_{3}\right)$ in mole\% with $500 \mathrm{ppm} \operatorname{Pr}_{2} \mathrm{~S}_{3}$, prepared by a conventional vacuum sealed silica ampoule approach. When initially examined by using a microscope (without any preliminary treatment) there was no sign of any crystalline phase. However, after etching, it was clear that this sample contained crystallines in the glass matrix with a different size, shape and much higher concentration than sample $B$ (fig.1.b). We carried out x-ray diffraction analysis of sample $\mathrm{C}$ and identified these crystal features as as $\alpha-\mathrm{Ga}_{2} \mathrm{~S}_{3}$. This identification is shown in fig. 2 where the experimental results of the x-ray analysis basically reproduce the expected pattern (whose peaks are represented in the figure by vertical lines) for a $\alpha-\mathrm{Ga}_{2} \mathrm{~S}_{3}$ crystal phase. The small shift between peaks and lines is probably due to presence of impurities or perhaps the dopants (impurity ions can substitute $\mathrm{Ga}^{3+}$ in the $\alpha-\mathrm{Ga}_{2} \mathrm{~S}_{3}$ and this is more likely to occur when they have comparable size with the original ions). On the contrary the x-ray analysis for sample B did not show any peaks although microcrystals were present (fig. 1.a). This is likely to be associated with the fact that the density of these microcrystals was much lower compared to sample $\mathrm{C}$, thus not allowing the resolution of any peak. However, using energy dispersive spectroscopy and electron microscopy, we found that the microcrystals in sample B were essentially made of $\mathrm{Ga}, \mathrm{La}, \mathrm{S}$ in about the same proportion as the glass matrix.

The SHG experiments were carried out

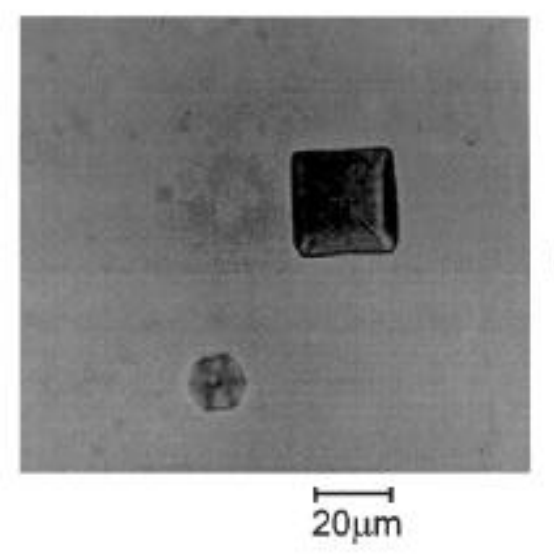

(a)

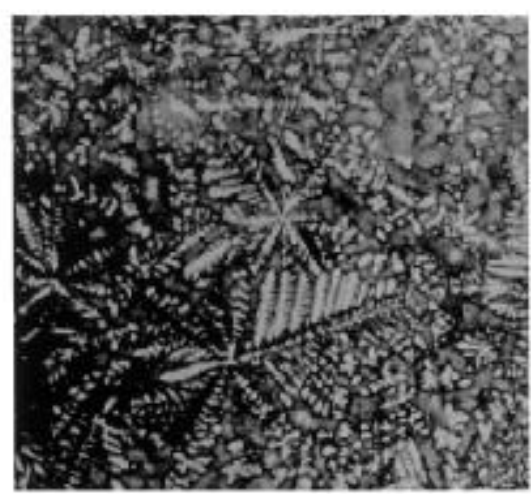

(b)

Figure 1 Microcrystals in Ga:La:S glass:

(a) in sample $B$, (b) in sample $C$. Note the difference in size, density and shape of the crystal phase (pictures a and $b$ are on the same scale).

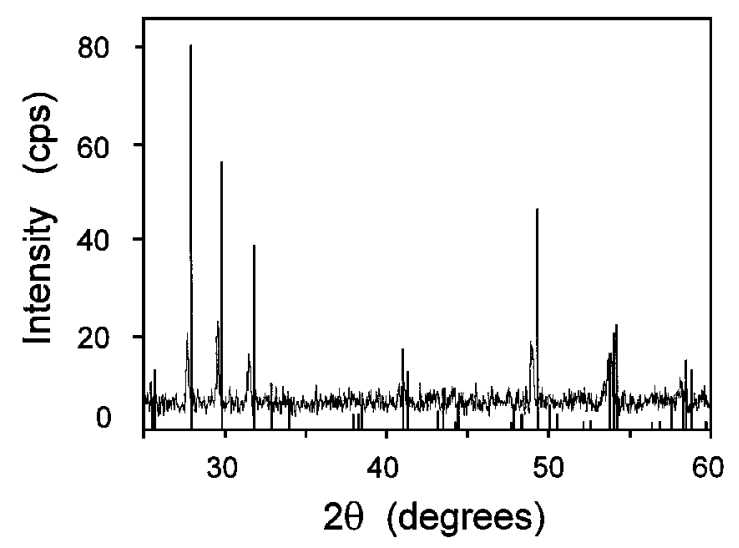

Figure 2 X-ray diffraction analysis for sample

$C$. The vertical lines represent the peaks expected for the $\alpha$-phase of $\mathrm{Ga}_{2} \mathrm{~S}_{3}$. The small shift between lines and actual peaks is probably due to presence of low-level impurities. 
using as fundamental source a 1.064 $\mu \mathrm{m} \mathrm{Nd}$ :YAG laser, which was Q-switched at a repetition rate of $1 \mathrm{kHz}$, each pulse consisting of a train of $~ 30$ mode-locked pulses (each separated by 10ns) of $\sim 300 \mathrm{ps}$ pulse duration across the $\sim 300$ ns intensity FWHM of the Q-switched envelope. The beam was then focused into the sample to a spot size $\left(1 / \mathrm{e}^{2}\right.$ intensity radius) of $30 \mu \mathrm{m}$. Sample A, which was free of microcrystals, did not show any $\mathrm{SH}$ signal, while samples $\mathrm{B}$ and $\mathrm{C}$, whose structure contained microcrystals, produced evident SHG (see fig.3). We excluded that the generated green light was associated with luminescence since its spectrum was centered at $532 \mathrm{~nm}$ and had a bandwidth less than $0.2 \mathrm{~nm}$.

When sample B was moved transversely to the beam, the $\mathrm{SH}$ signal changed rapidly from regions where it was completely absent to regions where it

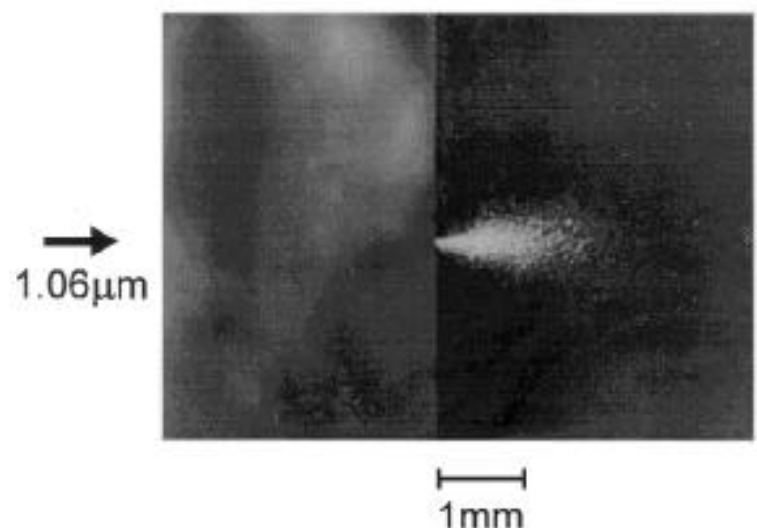

Figure 3 Second harmonic track in sample $C$ (lateral view). It is evident the scattering of the $\mathrm{SH}$ beam from the microcrystal. The thickness of sample $C$ was afterwards reduced to $0.1 \mathrm{~mm}$ in order to allow $\mathrm{SH}$ measurements.

reached maximum values. Using a white light source we imaged on a CCD camera one of the regions where the SH signal had a maximum, confirming clearly that microcrystals were responsible for the frequency doubling process. Fig.4 shows the SH signal intensity as a function of the polarization orientation (rotation in a plane perpendicular to the beam) of the fundamental beam linearly polarized. This dependence indicates the existence of a preferential direction for the SH interaction, a common feature for second-order nonlinear crystals.

Unlike sample B, the SH signal produced by sample $\mathrm{C}$ was rather uniform over the whole transverse section. Also no strong polarization dependence was observed. These results on SH signal uniformity and polarization dependence for sample B and $\mathrm{C}$ are not surprising, considering that the beam has transverse dimensions of tens of microns: in sample $\mathrm{B}$ the interaction basically occurs with a single-crystal (fig.1.a) while in sample $\mathrm{C}$ with many crystals, randomly distributed and oriented (fig. 1.b).

The maximum $\mathrm{SH}$ average power detected was $\sim 10 \mathrm{nW}$ and $0.5 \mu \mathrm{W}$ for sample B and C respectively, corresponding to an average fundamental power of $100 \mathrm{~mW}\left(\sim 0.7 \mathrm{GW} / \mathrm{cm}^{2}\right.$ peak intensity). As reference, we have

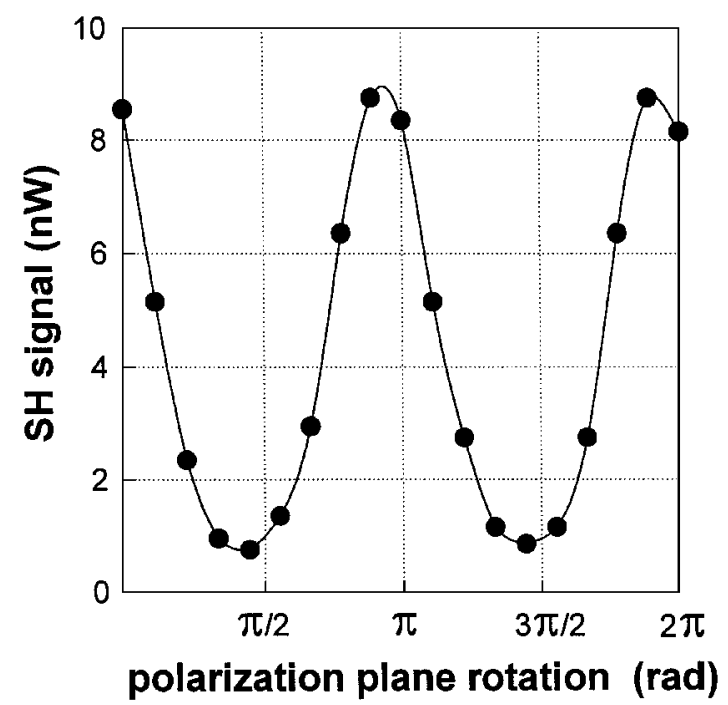

Figure 4 Polarization dependence of SH signal for sample $B$. There is a strong indication of a preferential direction for the $\mathrm{SH}$ interaction. In sample $C$ there was not any significant polarization dependence. 
measured in quartz crystal a SH signal of $\sim 2 \mathrm{nW}$ for the same fundamental power. The SH powers reported here were maximised by tilting the samples and by rotating the polarization of the fundamental beam. Sample C produced a higher SH signal than sample B although their thicknesses were $\sim 0.1 \mathrm{~mm}$ and $3 \mathrm{~mm}$ respectively. We believe that this is probably due to the fact that in sample $\mathrm{C}$ there is a collective contribution from different $\alpha-\mathrm{Ga}_{2} \mathrm{~S}_{3}$ crystals invested by the fundamental beam [12]. Instead, in sample B, this cumulative growth for the SH signal could be prevented by the low Ga:La:S crystal concentration. In conclusion, we have investigated second harmonic generation in Ga:La:S based glasses. Our experimental observations identify Ga:La:S and $\alpha-\mathrm{Ga}_{2} \mathrm{~S}_{3}$ crystals as responsible for the frequency doubling process. These results suggest that $\mathrm{Ga}: \mathrm{La}: \mathrm{S}$ based glasses, free of crystalline phases, should not show second order nonlinearity. Therefore, for optical amplifiers applications, where microcrystallines features have to be in any ease absent in order to keep the scattering losses at low levels, second-order nonlinear processes should not constitute a major problem. Further investigations are required for a complete understanding of the increase in SH signal in sample $\mathrm{C}$ and this could be exploited to fabricate in a controlled way Ga:La:S glasses with dispersed microcrystals, suitable for efficient second-order nonlinear processes. For example the modulation of the nonlinearity via an appropriate periodic orientation of these microcrystals could provide quasi-phase-matching, thus giving efficient interaction [13].

We would like to thank Prof. Mark T.Weller of the Chemistry Department, University of Southampton, for carrying out the x-ray diffraction analysis. The Optoelectronics Research Centre is an Interdisciplinary Research Centre, partly supported by a grant from the U.K. EPSRC. Chalcogenide starting materials were supplied by Merck (UK) Ltd.

\section{References}

1. U.Orsterberg and W.Margulis, Opt. Lett. 11, 516 (1986).

2. $\quad$ R.H.Stolen and H.W.K.Tom, Opt. Lett. 12, 585 (1987).

3. E.M.Dianov, P.G.Kazansky, D.Yu Stepanov, Sov. J. Quantum Elect.19, 575 (1989).

4. $\quad$ R.A.Myers, N.Mukherjee and S.R.J.Brueck, Opt. Lett. 16, 1732 (1991).

5. A.Okada, K.Ishii, K.Mito and K.Sasaki, Appl. Phys. Lett. 60, 2853, (1992).

6. P.G.Kazansky, L.Dong and P.St.J.Russell, Opt. Lett. 19, 701 (1994).

7. P.N.Kumta and S.H.Risbud, J. Mater. Sci. 29, 1135 (1994).

8. D.W.Hewak, R.S.Deol, J.Wang, G.Wylangowski, J.A.Medeiros Neto, B.Samson, R.I.Laming, W.S.Brocklesby, D.N.Payne, A.Jha, M.Poulain, M.Otero, S.Surinach and M.D.Baro, Elect. Lett. 29, 237, 1993.

9. M.T.de Araujo, M.V.D.Vermelho, A.S.Gouveia-Neto, A.S.B.Sombra and J.A.Medeiros Neto, Phot. Tech. Lett. 8, 821 (1996). 
10. G.Collin, J.Flahaut, M.Cuittard and A.M.LOireau-Lozach, Mat. Res. Bull. 11,285 (1976).

11. M.P.Pardo, L.Dogguy-Smiri, J.Flahaut and N.Huy Dung, Mat. Res. Bull. 16, 1375 (1981).

12. $\quad$ S.K.Kurtz and T.T.Perry, J. Appl. Phys. 39, 3798 (1968).

13. J.A.Armstrong, N.Bloembergen, J.Ducuing and P.S.Pershan, Phys. Rev. 127, 1918 (1962). 